\title{
Physical-based rainfall-triggered shallow landslide forecasting
}

\author{
Yung-Chia Hsu', Yin-Lung Chang ${ }^{1 *}$, Che-Hao Chang ${ }^{2}$, Jinn-Chuang Yang ${ }^{3}$ and Yeou-Koung Tung ${ }^{3}$
}

\author{
* Correspondence: \\ ylchang88@gmail.com \\ ${ }^{1}$ National Taiwan University, Taipei \\ City, Taiwan \\ Full list of author information is \\ available at the end of the article
}

\begin{abstract}
This study demonstrates the applications of two physical-based early warning methods for rainfall-induced shallow landslide and compare their relative performance. One method is rainfall threshold-based method and the other method is by real-time simulation. The former establishes landslide threshold in advance using 50 historical rainfall events, in conjunction with physical-based rainfall-triggered shallow landslide model, to evaluate the stability of a concerned slope. Quantitative precipitation estimation (QPE) for nowcast is used in the rainfall threshold-based method for landslide predictions. The latter method also applies rainfall-triggered landslide model in real-time simulation by feeding QPE and quantitative precipitation forecast (QPF) of specified lead-time. Both methods are integrated into an early warning system (e.g. Delft-FEWS) for real-time nowcast and/or forecast purposes. The two shallow landslide early warning methods are applied to a slope in the vicinity of a highway section in Taiwan. Comparisons between the two methods are made to evaluate their performance using rainfall data from three past typhoon events. Despite of some discrepancies found in the results, both methods can predict landslide quite consistently. Without sufficient number of actual landslide records for model validation, the true accuracy of both landslide early warning methods cannot be assessed. However, the consistency of predicted landslide occurrence times during three historical typhoon events in the case study indicated that they could be viable for providing good supportive information for decision-making in landslide hazard mitigation.
\end{abstract}

Keywords: Rainfall-triggered shallow landslide, Real-time forecast, Early warning, Landslide modeling

\section{Introduction}

Factors influencing slope stability can be classified into two categories: latent factors and driving factors (Dai et al. 2002). The former includes those hydrologic, physiographic, and geologic conditions defining the stability state of a slope, such as groundwater table, soil properties, slope geometry and vegetation cover, etc. The latter considers those triggering forces to destabilize a slope, such as rainfall and earthquakes. Among the various triggering forces rendering slope failure, rainfall is the primary culprit. Petley (2008) indicated that rainfall-triggered landslides are responsible for about $90 \%$ of fatalities associated with slope failures. Taiwan is an island state, located in Southeast Asia, with about two-third of her land mass covered by mountains. By having an average annual rainfall about $2500 \mathrm{~mm}$ and being located on typhoon paths with an average of 4-5 typhoon visits per year, landslide incidents are common

(c) The Author(s). 2018 Open Access This article is distributed under the terms of the Creative Commons Attribution 4.0 International License (http://creativecommons.org/licenses/by/4.0/), which permits unrestricted use, distribution, and reproduction in any medium, provided you give appropriate credit to the original author(s) and the source, provide a link to the Creative Commons license, and indicate if changes were made. 
during the wet season (April-September). A single typhoon event can sometimes bring intense rainfall over $1000 \mathrm{~mm}$ in mountainous regions. Intense rainfall often triggers disastrous landslides that cause damage to infrastructures, mudflows, and human casualties. Moreover, Taiwan geologically lies on a complex tectonic boundary between Eurasian and Oceanic Plates. Major seismic faults in Taiwan generate earthquakes, which loosen up soil mass making a slope even more susceptible to slide under rainfall.

To effectively mitigate landslide hazards, real-time simulation and forecast of rainfall-triggered landslide potential during a storm event are both urgent and necessary. Piciullo et al. (2018) categorize landslide early warning systems, according to the scale of analysis, into local and territorial systems. The former addresses landslide failure at a slope scale whereas the latter covers over a wide area at regional scale. In terms of methods for landslide early warning, van Westen et al. (2006) categorized the methods into three types including heuristic, statistical and deterministic methods. Heuristic methods are based on landslide records in a region by directly correlating pertinent landslide instigating factors with the landslide potential through some empirical relationships. Thus, the landslide instigating factors used can be different from region to region and from one expert to another. Heuristic methods, in general, are relatively simple to use, but involve significant subjectivity in judgement. Hence, landslide prediction for a slope by a heuristic method can vary by different experts.

Statistical methods, such as threshold-based methods using rainfall intensity-duration, are developed mostly from multivariate statistical analyses of available record on failed slopes to investigate the combined effect of triggering factors that caused landslides. Statistical methods (Carrara 1988; Carrara et al. 1992; Lee and Choi 2004; Ermini et al. 2005; Wang et al. 2009; Segoni et al. 2014; Iadanza et al. 2016; Piciullo et al. 2018) are often applied to a region of similar terrain conditions once the relationships between triggering factors and landslide are established. Nonetheless, once the triggering forces or geologic conditions change, such as land use or climate, the established relations may fail to provide valid prediction. Moreover, the major deficiency of statistical methods is that they often do not take into account the time occurrence of landslide. Hence, statistical methods can only be used to predict whether a slope would or would not fail instead of predicting when the slope would fail. Estimating slope failure time is a key element dictating the accuracy of issuing an early warning.

To circumvent the above-mentioned shortcoming of statistical methods for not being able to predict the time of slope failure, rainfall-triggered landslide warning threshold relation can be established through the application of deterministic physical-based landslide simulation models (Salciarini and Tamagnini 2015; Schilirò et al. 2015). Using a physical-based landslide simulation model, one can use factor of safety (FS) to indicate the state of a slope. When a slope is stable, FS value is greater than unity. On the other hand, a slope is unstable when FS value is lower than unity. During a rainstorm event the value of FS of the slope would be decreasing with time as more rainwater infiltrates into the soil medium. The time when FS value reaches the critical value of unity, the slope could be on the verge of failure. Thus, deterministic methods by applying physical-based slope stability simulation models can provide quantitative assessment about the state of slopes under the influential factors considered at the time of simulation. In this study, an unsteady rainfall infiltration model based on the Richards equation for saturated and unsaturated soil media is applied for slope stability analysis. 
Taking the advantages of both statistical methods for its easy implementation and physical-based shallow landslide simulation models for estimating slope failure time, the rainfall thresholds for landslide occurrence can be established for a concerned slope from historical/synthesized rainfall events. Unlike rainfall threshold-based methods that uses the historical/synthesized rainfall events, the real-time simulation method can be an alternative by directly incorporating nowcast and forecast rainfall data in a slope stability analysis model to simulate time varying stability state of a concerned slope.

The objective of this study is to present an investigation of two local landslide early warning methods (i.e., rainfall threshold-based method and real-time simulation method) utilizing physical-based slope stability analysis model. To compare the landslide forecast capability of the two methods for early warning purpose, this study applies both methods to predict the landslide occurrence time of a chosen slope site in Taiwan during three typhoon rainfall events.

\section{Study site}

The study site is located on Taiwan Highway No. 18 (T-18 Highway) in Alishan Mountain resort area (Fig. 1) in Southern Taiwan. The slopes along T-18 Highway mostly are steeper than $30 \%$. The concerned slope in the study site can be divided into upper and lower slopes according to their distinct geometric features. Based on the site investigation done by the Traffic and Transportation Bureau of Taiwan, the upper and lower parts of the concerned slope are colluvium soil composed of stones of irregular sizes, sand and clay. Borehole data show that the colluvium soil medium of the slopes has a thickness ranging 1.5-4.5 m with an averaged value of $2.5 \mathrm{~m}$. The groundwater table can rise to about $1 \mathrm{~m}$ under the slope surface in the rainy season. The soil parameters in the study area are listed in Table 1.

Figure 2 shows the annual rainfall during 1980-2012 in the region ranging from 1900 to $5500 \mathrm{~mm} / \mathrm{yr}$. with an average of $3250 \mathrm{~mm} / \mathrm{yr}$. The rainfall concentrates in

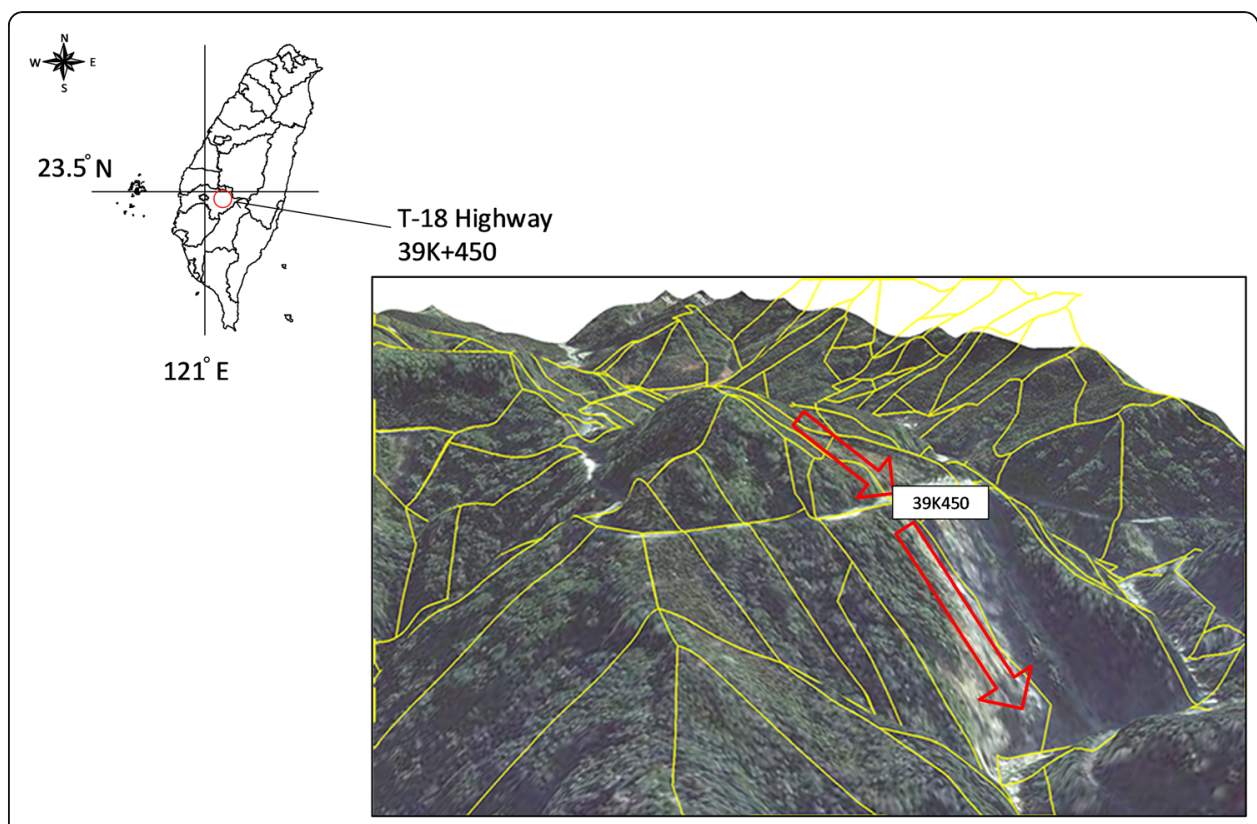

Fig. 1 Location of the concerned slopes 
Table 1 Representative soil parameters for slopes in the study area

\begin{tabular}{ll}
\hline List of Parameters & Range \\
\hline Specific weight $\left(G_{s}\right)$ & 2.65 \\
Friction angle $\left(\varphi^{\prime}\right)$ & $26^{\circ}$ \\
Cohesion $\left(C^{\prime}\right)$ & $500 \mathrm{~N} / \mathrm{m}$ \\
Residual water content $\left(\theta_{r}\right)$ & $17 \%$ \\
Saturated water content $\left(\theta_{s}\right)$ & $47 \%$ \\
Hydraulic conductivity $\left(K_{s}\right)$ & $75 \mathrm{~cm} /$ day \\
Soil-water retention parameter $(N)$ & 1.8 \\
Soil-water retention parameter $(\zeta)$ & 0.01 \\
\hline
\end{tabular}

May-September because of monsoons and typhoons (Fig. 3) and this is the time period when most rainfall-induced landslides occur.

\section{Physical-based rainfall-triggered landslide models}

To simulate the rainfall-triggered shallow landslide, rainfall infiltration process must be considered in the slope stability analysis model. Several studies have developed physical-based numerical models based on the Richards equation to describe rainfall seepage into the slopes (Cai and Ugai 2004; Gabet and Dunne 2003; Tsai 2008; Tsai and Wang 2011). Many of these models are further coupled with the extended Mohr-Coulomb failure criterion (Fredlund et al. 1978) to investigate shallow landslide of unsaturated soil (e.g., Tarantino et al. 2000; Collins and Znidarcic 2004; Tsai et al. 2008). Sometimes, models for nearly saturated soil were used for rain-triggered shallow landslides assessment (Iverson 2000; Crosta and Frattini 2003; Keim and Skaugset 2003; Frattini et al. 2004; Lan et al. 2005; D'Odorico et al. 2005; Tsai and Yang 2006). The software model, TRIGRS (Transient Rainfall Infiltration and Grid-based Regional Slope-Stability Analysis), integrates Iverson's model for nearly saturated soil medium with geographic information system (Baum et al. 2002).

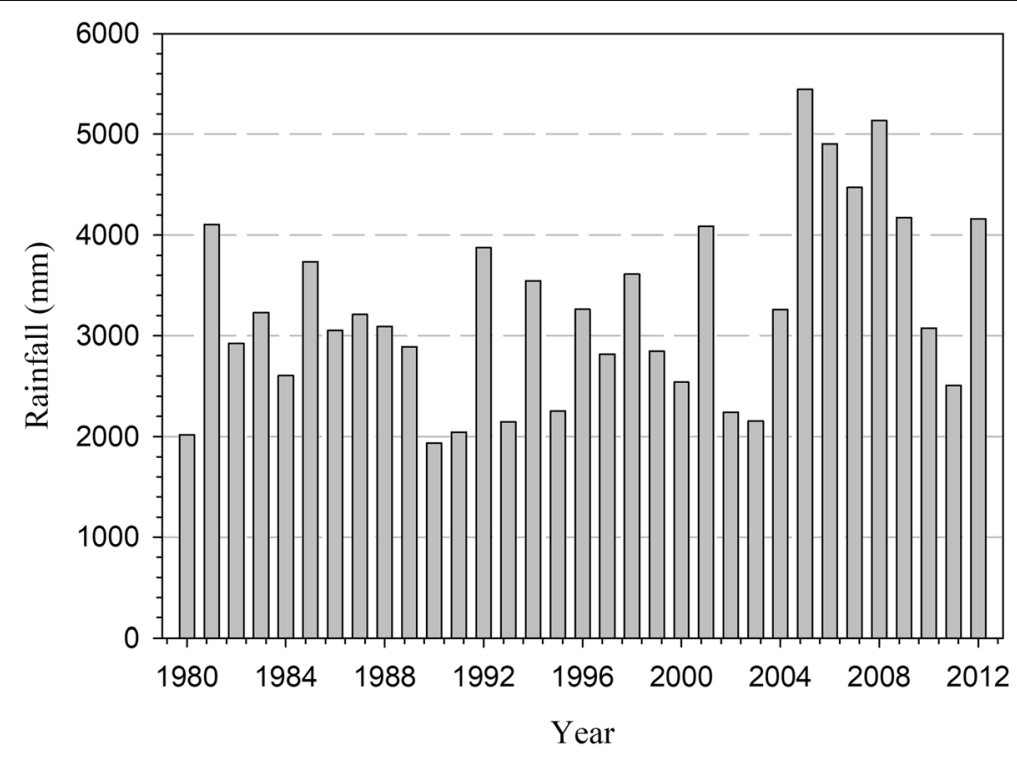

Fig. 2 Annual rainfall amounts during 1980-2012 in the study area 


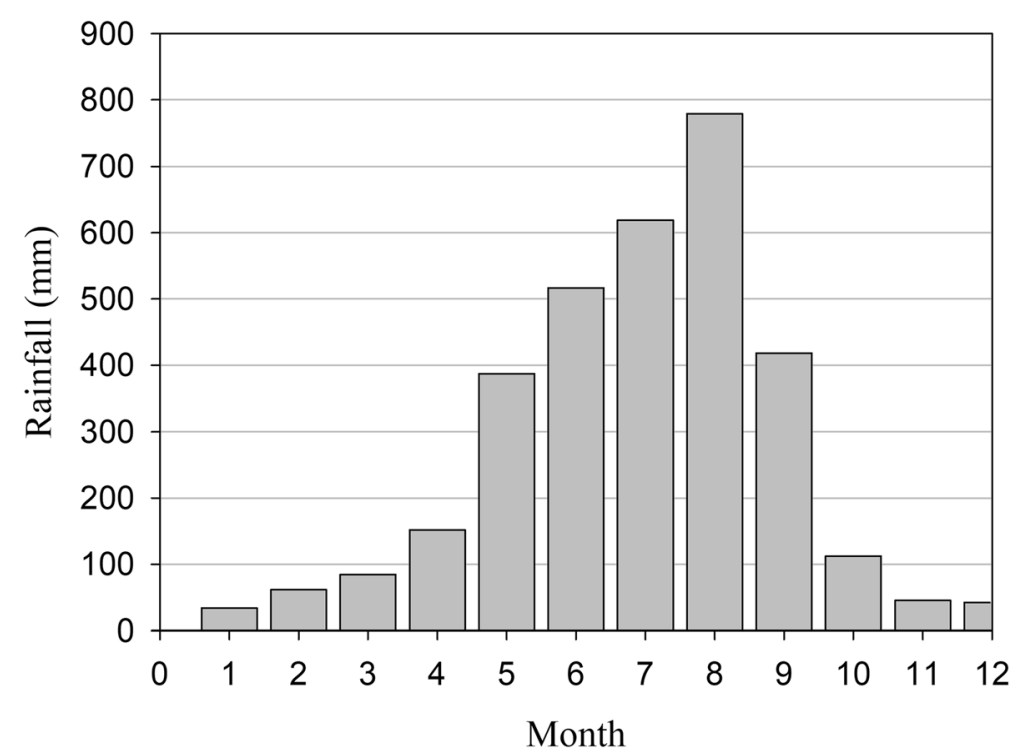

Fig. 3 Average monthly rainfall in the study area

By taking into account pore water pressure distribution, many studies (Wu and Sidle 1995; Iverson 2000; Tsai and Yang 2006; Tsai et al. 2008) integrate steady or transient sub-surface flow simulation models into slope stability analysis to evaluate the FS of an infinite slope. Tsai and Yang (2006) indicated that the Iverson model (2000) might inaccurately produce pore water pressure distribution under the ponding condition and made the modification accordingly. The modified Iverson model was applied to investigate the influences of rainfall patterns on shallow landslides in saturated soils (Tsai 2008) and unsaturated soils (Tsai and Wang 2011). In this study, unsaturated soil seepage model of Tsai and Wang (2011) is used to calculate time variation of pore water pressure distribution in the soil medium in a slope subject to potential failure in a rainstorm event.

\section{Landslide infiltration model}

The landslide infiltration model on slope is described by the Richards equation for unsaturated soil medium:

$$
\frac{\partial \psi}{\partial t} \frac{d \theta}{d \psi}=\frac{\partial}{\partial x}\left[K_{L}(\psi)\left(\frac{\partial \psi}{\partial x}-\sin \alpha\right)\right]+\frac{\partial}{\partial y}\left[K_{L}(\psi) \frac{\partial \psi}{\partial y}\right]+\frac{\partial}{\partial z}\left[K_{z}(\psi)\left(\frac{\partial \psi}{\partial z}-\cos \alpha\right)\right]
$$

where $\psi=$ groundwater pressure head $(\mathrm{m}) ; \theta=$ volumetric water content; $\alpha=$ slope angle $\left({ }^{\circ}\right)$; and $t=$ time (sec); $K_{L}, K_{z}=$ hydraulic conductivity in lateral and slope-normal directions $(\mathrm{m} / \mathrm{s})$, respectively. For shallow slope and vertical rainfall infiltration, Eq. (1) can be simplified to:

$$
C(\psi) \frac{\partial \psi}{\partial t}=\left(\cos ^{2} \alpha\right) \frac{\partial}{\partial z}\left[K_{z}(\psi)\left(\frac{\partial \psi}{\partial z}-1\right)\right]
$$

in which $C(\psi)=d \theta / d \psi$, the change in volumetric water content per unit change in groundwater pressure head $\left(\mathrm{m}^{-1}\right)$. Tsai and Wang (2011) develop a numerical model for solving transient pore water pressure distribution inside a shallow slope due to rainfall infiltration with the specified initial and boundary conditions. 


\section{Slope stability model}

Pore water pressure and soil moisture content distribution inside a slope can be used to calculate the FS of the slope by the infinite slope stability analysis (Tsai et al. 2008):

$$
\begin{aligned}
& F S(t)=\frac{\tan \left(\phi^{\prime}\right)}{\tan (\alpha)}+\frac{c^{\prime}-\gamma_{w} \Psi_{c}(t) \mathrm{X} \tan \left(\phi^{\prime}\right)-\gamma_{w} \Psi_{p}(t) \tan \left(\phi^{\prime}\right)}{\bar{\gamma} Z \sin (\alpha) \cos (\alpha)} \\
& X=\frac{\theta-\theta_{r}}{\theta_{s}-\theta_{r}}
\end{aligned}
$$

in which $\phi^{\prime}=$ effective friction angle $\left(^{\circ}\right) ; c^{\prime}=$ effective cohesion $\left(\mathrm{N} / \mathrm{m}^{2}\right) ; \gamma_{w}=$ unit weight of water $\left(\mathrm{N} / \mathrm{m}^{3}\right) ; \chi=$ effective stress parameter; $\theta_{r}$ and $\theta_{s}$ are the saturated and residual volumetric water contents, respectively; $\bar{\gamma}=$ depth-averaged unit weight of soil $\left(\mathrm{N} / \mathrm{m}^{3}\right)$, which can be expressed as:

$$
\bar{\gamma}=\frac{1}{Z} \int_{0}^{z}\left\{[1-\theta(\zeta)] \gamma_{w} G_{s}+\theta(\zeta) \gamma_{w}\right\} d \zeta
$$

where $G_{s}=$ specific gravity of soil solid. Landslides can happen in both saturated and unsaturated conditions. In Eq. (3), when the groundwater pressure head is negative (i.e., the soil is unsaturated), $\Psi_{c}$ is equal to $\Psi$ which can be obtained from Eq. (2), whereas $\Psi_{p}$ is zero. On the contrary, $\Psi_{p}$ is identical to $\Psi$, and $\Psi_{c}$ is zero while the groundwater pressure head is positive (i.e., the soil is saturated).

By using the calibrated rainfall-triggered landslide model of Tsai and Wang (2011) for the study site, Fig. 4 shows the landslide potential maps, in terms of FS, for the slopes in the vicinity of the road section at T-18 Highway under design rainfall amounts of 200-mm and 600-mm.

\section{Landslide forecasting methods}

\section{Physical-based rainfall threshold-based method}

The physical-based rainfall threshold-based method takes the advantages of both statistical-based threshold and physical-based deterministic methods. The method involves following steps (see Fig. 5):

Step-(1): Select sufficient number of historical rainstorm events having high potential to cause slope failure in the study area;

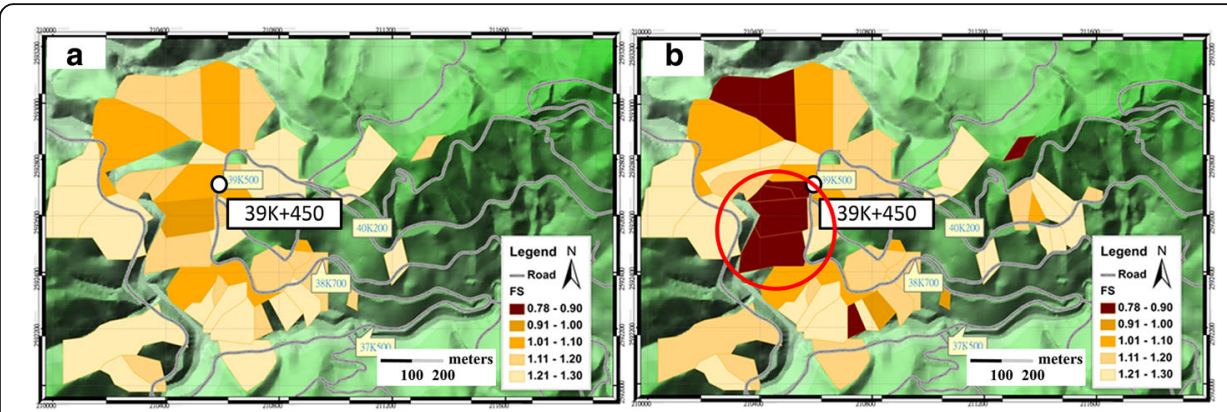

Fig. 4 Landslide potential maps for the slopes in the vicinity of T-18 Highway under design rainfall amount of (a) 200-mm, (b) 600-mm rainfall scenarios 


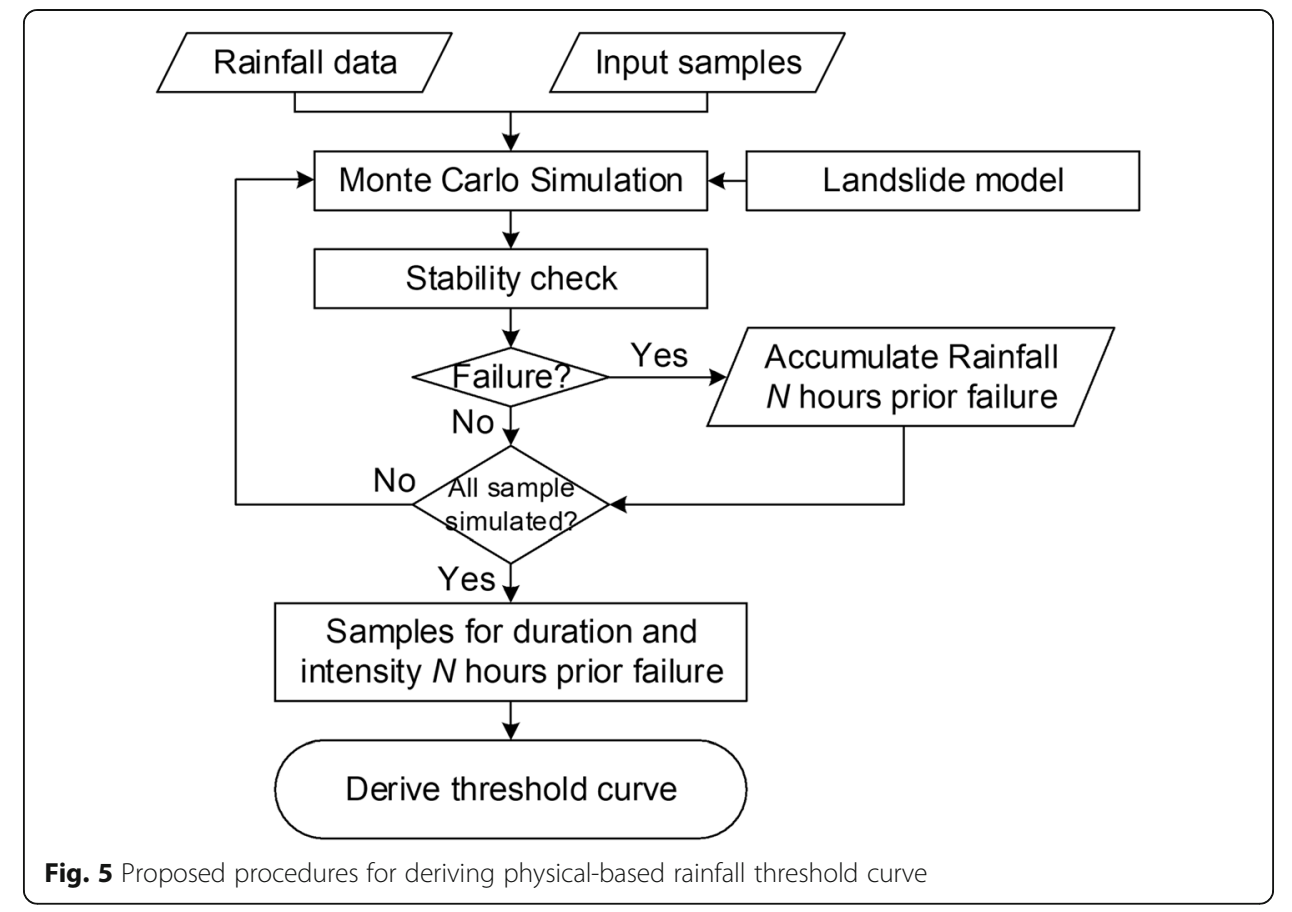

Step-(2): Based on the statistical features of soil parameters in the study area, generate sufficient number of representative soil parameters for the concerned slopes. Based on a few soil samples available around the concerned slope site, soil parameters were found weakly correlated. Hence, they are treated as independent variables in the process of generating soil parameters. In case that soil parameters are significantly correlated, proper multivariate procedure is required to generate representative soil parameters; Step-(3): Randomly match a rainstorm event with a synthesized soil parameter set. Use them in the chosen deterministic landslide model to identify slope failure time, $t_{f}$ at which FS $=1.0$.

Step-(4): Extract average rainfall intensity from the beginning of storm to time $t_{f}-t_{l}$ (see Fig. 6) with $t_{l}$ being the concerned lead-time.

Step-(5): Repeat Step (3)-(Carrara et al. 1992) for all synthesized rainstorm events to establish database for average rainfall intensity and $t_{f}-t_{l}$ for different lead-time $t_{l}$ based on which empirical landslide threshold curves are established by regression analysis.

Figure $7 \mathrm{a}$ is the zero lead-time $\left(t_{l}=0\right)$ warning curve for landslide occurrence of the concerned slope. This implies that, when the average rainfall intensity for a storm event touch the curve in Fig. 7a, it is anticipated that slope failure would occur because there is no early warning. The failure threshold curve is established by regression analysis based on the average intensity-duration points (in Fig. 6) with $\mathrm{FS}\left(t_{f}\right)=1$ produced by the slope stability analysis model from 50 historical rainfall events of which not all the rainfall events could cause slope failure. The threshold curve with 3-h lead-time $\left(t_{l}=3\right)$ indicates that a 3-h warning can be made before landslide occurrence (see Fig. 7b)

Figure 8 shows the rainfall threshold curves of 0 - and 3-h lead-time for landslide occurrence for the upper and lower slopes at road section $39 \mathrm{~K}+450$ on T-18 Highway (i.e., red circle in Fig. 4b). The rainfall threshold curves of different lead times can be 


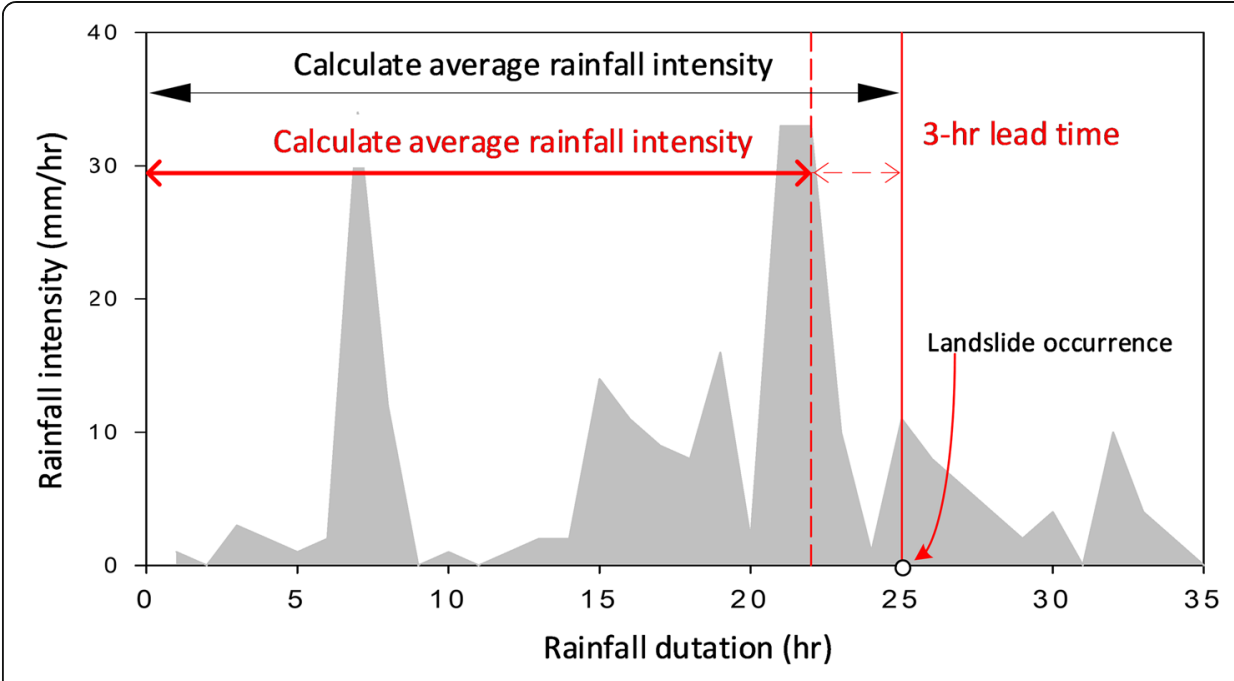

Fig. 6 Evaluating an average rainfall intensity for a landslide event

derived by the procedure described above based on 50 historical significant rainfall events in the study site.

As illustrated on the left half of Fig. 9, landslide occurrence at the study slopes with 3-h lead-time can be easily distinguished by evaluating the average rainfall intensity and duration from the real-time rainfall record or quantitative precipitation estimation (QPE). If an evaluated average rainfall intensity value approaches or passes the threshold curve, landslide of the concerned slope is likely to occur within $3 \mathrm{~h}$.

\section{Real-time simulation method}

By real-time simulation method, the slope stability analysis model is incorporated into Delft-FEWS (Delft - Flood Early Warning System), hereafter referred to as FEWS-landslide. As illustrated on the right-half of Fig. 9, FEWS-landslide requires nowcast or forecast rainfall data (i.e., QPE or QPF) as the input information. Then, FEWS can activate the Model Server to provide direct landslide nowcast and forecast values of FS of a slope with $0-3 \mathrm{~h}$ of lead-time (i.e., $\mathrm{FS}(\mathrm{t}), \mathrm{t}, \mathrm{t}+1, \mathrm{t}+2, \mathrm{t}+3$ ) to the decision makers for proper action.

Unlike the rainfall threshold-based method that uses the historical/synthesized rainfall observations, FEWS-landslide uses real-time rainfall nowcast and forecast for
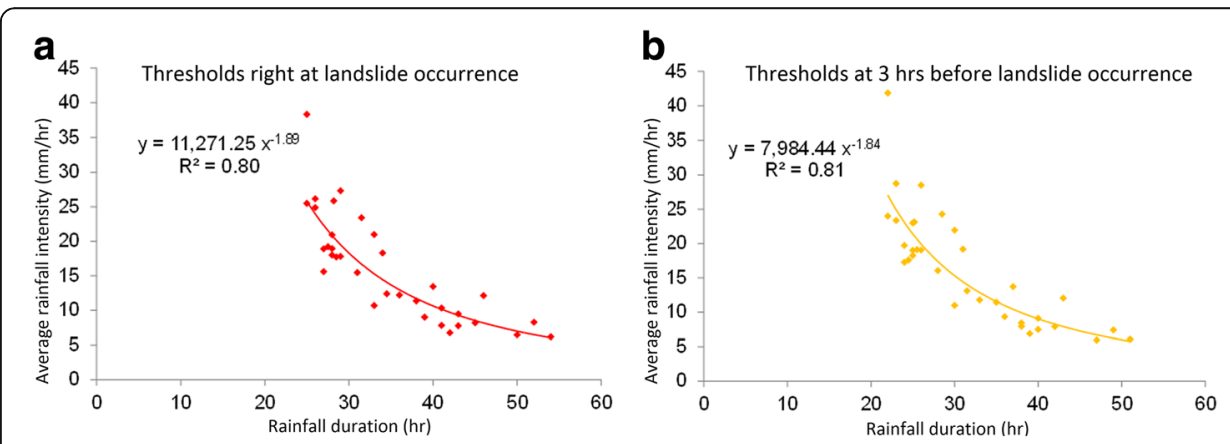

Fig. 7 0-3 h lead-time landslide threshold curves for the upper slope at $39 \mathrm{~K}+450$ on T18 Highway. a Thresholds right at landslide occurence, $\mathbf{b}$ Thresholds at $3 \mathrm{~h}$ before landslide occurence 


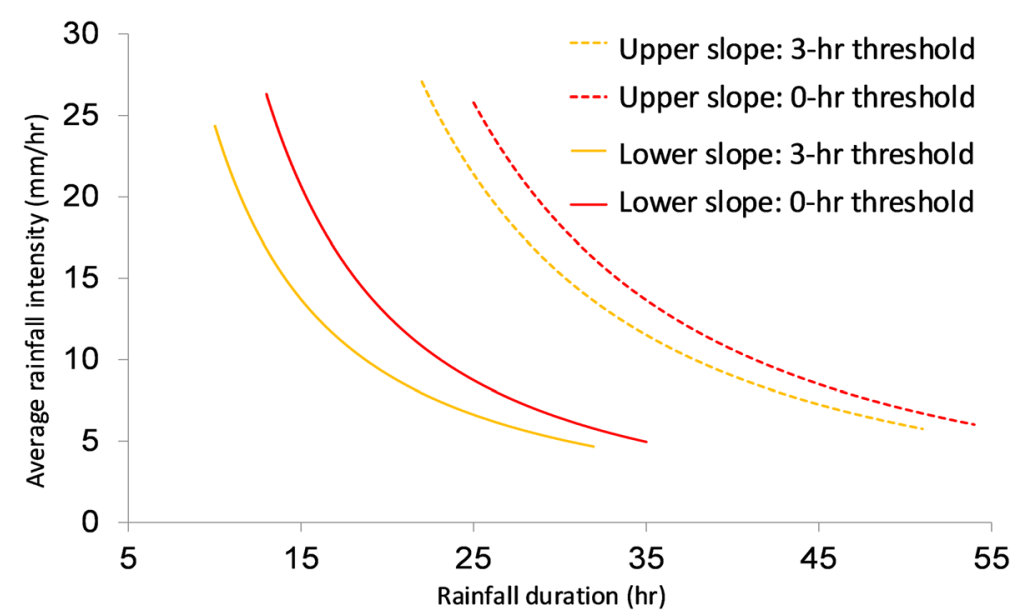

Fig. 8 0- and 3-h lead-time rain-induced landslide threshold curves for the upper and lower slopes at the study site

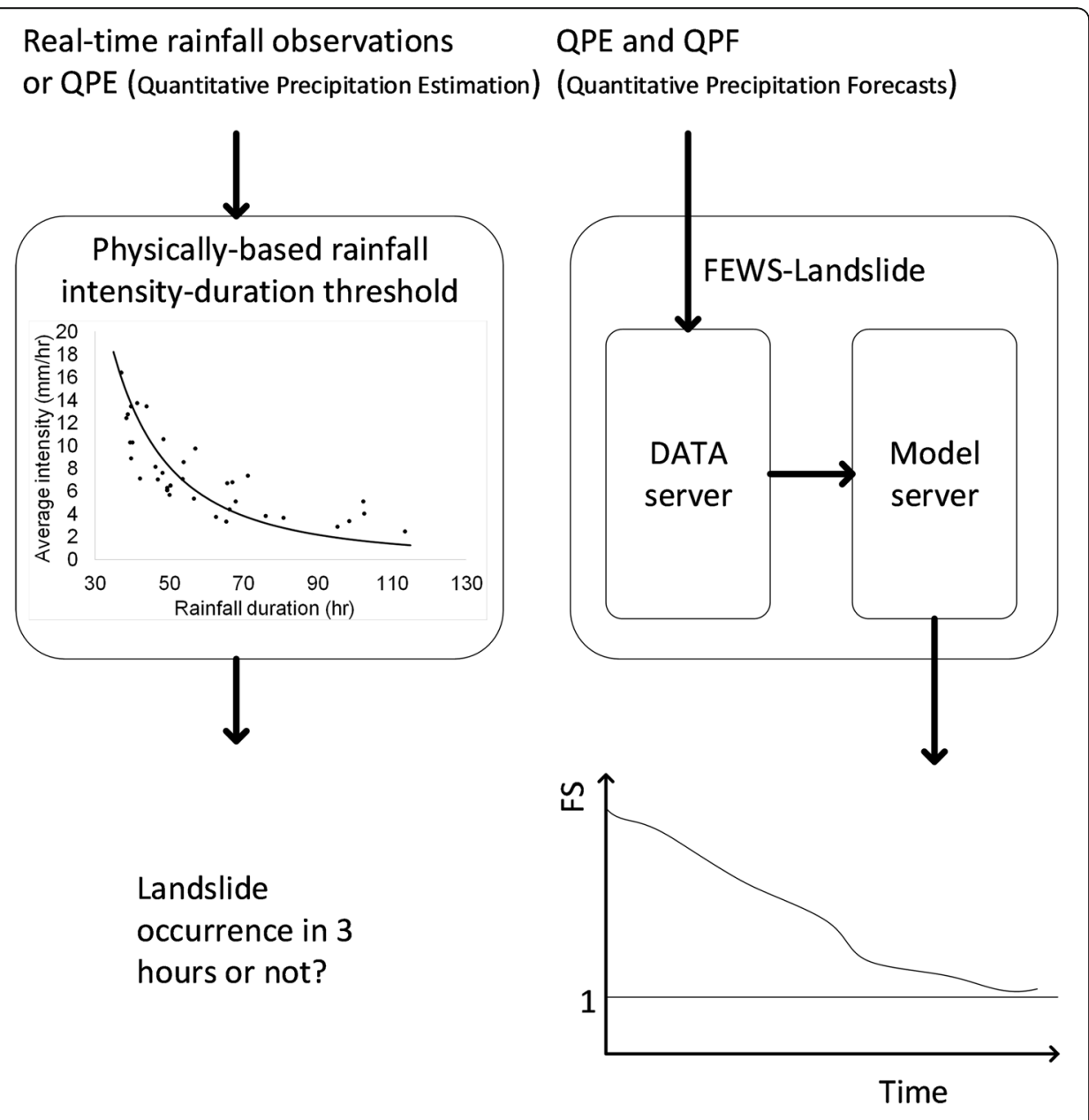

Fig. 9 Landslide forecasting by both physical-based threshold and real-time simulation methods 
simulation. Thus, the accuracy of the landslide forecast by the latter method would mostly rely on the accuracy of rainfall forecast and slope stability analysis model used to calculate slope FS with respect to time.

\section{Case study}

For illustration and comparison of the two landslide early warning methods, three typhoon rainfall events were used for estimating safety state of the concerned slopes. The three events considered are: Nanmadol (Aug 29-31, 2010), Saola (June 9-12, 2012), and Soulik (July 12-14, 2013). Rainfall data used in early warning include QPEs and QPFs with a 3-h lead-time for establishing rainfall threshold curves from the physical-based slope stability model and real-time simulation methods. The concerned slopes in the case study include both upper and lower slopes at road section $39 \mathrm{~K}+450$ on T-18 Highway.

In each rainfall event, FEWS-landslide uses both QPE and QPF for landslide nowcast and forecast with lead-time of 0 - and 3-h, respectively. When QPF yields a FS $<1$ at time $t_{f}$ and so does the QPE at time $t_{f}+3$, this indicates that landslide forecast for this storm event is "correct". As for the rainfall threshold-based method, when the rainfall intensity-duration trace of the QPE reaches above the 3-h lead-time threshold curve and 0-h threshold curve exactly after $3 \mathrm{~h}$, it also indicates a "correct" forecast for landslide. Otherwise, the forecast is regarded incorrect. It should be noted that, without actual records of landslides and failure times at the study slopes for verification, the phrase "correct forecast" used here means more closely to "consistent forecast" by the two early waning methods.

Figures 10, 11 and 12 illustrates landslide forecasts for the upper and lower slopes at road section $39 \mathrm{~K}+450$ on T-18 Highway by both early warning methods for the three typhoon events. The upper and lower parts of the two figures illustrate, respectively, the results given by FEWS-landslide and rainfall threshold-based methods.

\section{Typhoon Nanmadol}

For the upper slope at the selected road section, Remark-(a) in Fig. 10a demonstrates that FEWS-landslide method with a $t_{l}=3$-h forecast QPF input yields FS $<1$ at $t=26 \mathrm{~h}$, suggesting landslide occurrence at $t=29 \mathrm{~h}$. Also, FEWS-landslide method with a $t_{l}=0-\mathrm{h}$ nowcast QPE input indicates landslide occurrence at $\mathrm{t}=29 \mathrm{~h}$. Thus, FEWS-landslide method produce a consistent landslide forecast.

By the rainfall threshold-based method, Remark-(b) in Fig. 10a suggests that landslide would occur $3 \mathrm{~h}$ after $t=30 \mathrm{~h}$ in the upper slope. However, the rainfall intensity remains at a position lower than the $t_{l}=0$ - $h$ threshold curve as the rain continued. This means that, if warning is issued at $\mathrm{t}=30 \mathrm{~h}$, the rainfall threshold-based method might be in error.

For the lower slope at road section $39 \mathrm{~K}+450$, Fig. 10b shows that both rainfall threshold-based and FEWS-landslide methods indicate no landslide occurrence under both QPE and QPF rainfalls.

\section{Typhoon Saola}

For the upper slope at $39 \mathrm{~K}+450$ of $\mathrm{T}-18$ Highway, Fig. 11a shows that FEWS-landslide method with the $t_{l}=3$-h QPF input gives $\mathrm{FS}<1$ at $t=14 \mathrm{~h}$, suggesting that landslide would occur at $t=17 \mathrm{~h}$. FEWS-landslide method with the $t_{l}=0$-h nowcast 


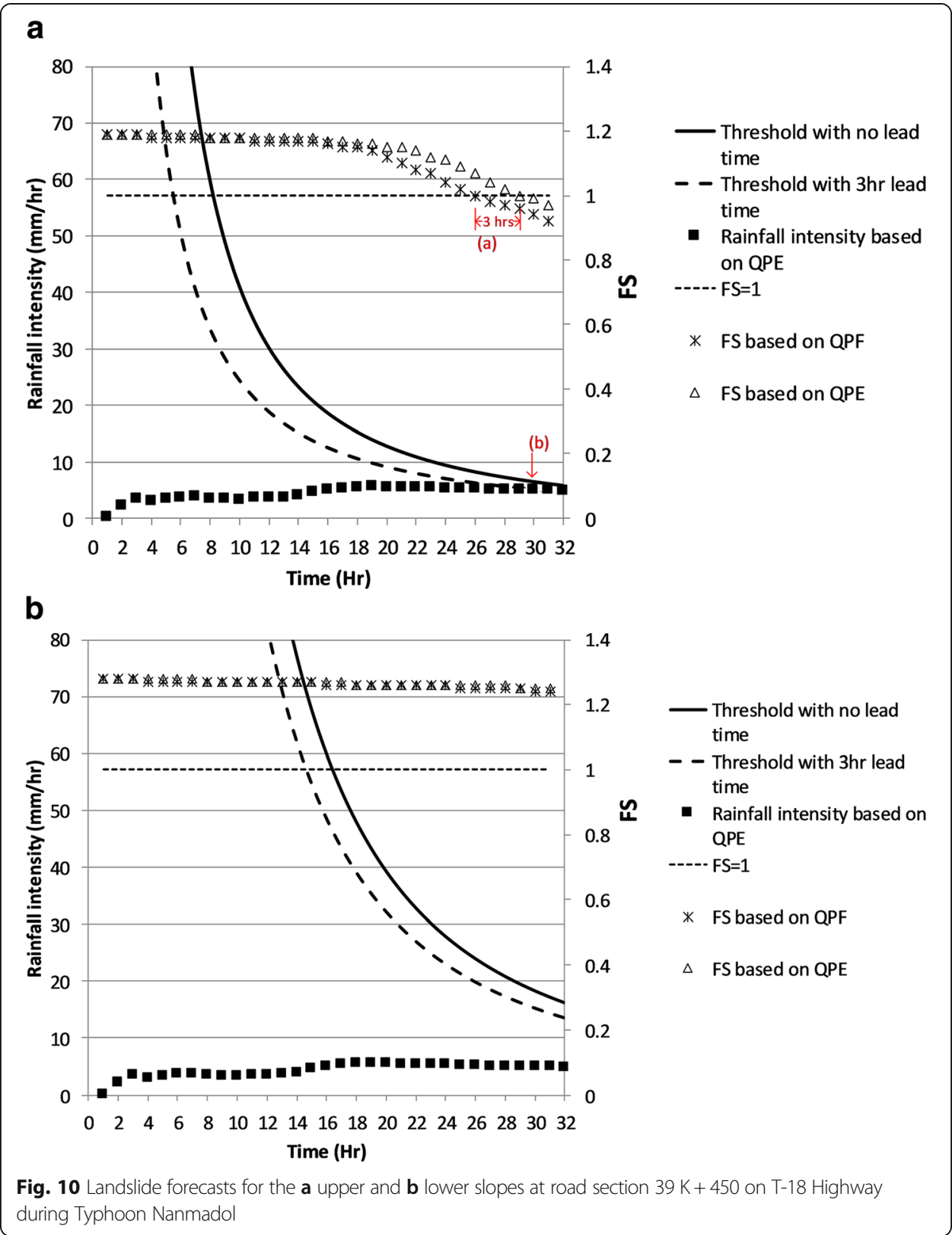

QPE input also indicates that landslide occurs at $\mathrm{t}=17 \mathrm{~h}$. Thus, FEWS-landslide method can make accurate landslide forecast.

As for the rainfall threshold-based method, Fig. 11a suggests that landslide would occur $3 \mathrm{~h}$ after $\mathrm{t}=14 \mathrm{~h}$. However, the rainfall intensity-duration trace curve meets the $t_{l}=0$-h threshold curve at $t=16 \mathrm{~h}$, rather than at $\mathrm{t}=17 \mathrm{~h}$, indicating that landslide occurs 1-h sooner than the expected. Nonetheless, the forecast accuracy in this case is still acceptable. However, this result raises an interesting issue about the reliability of landslide warning. Coincidentally, both methods in this case produce identical time instant to issue a 3-h lead-time landslide warning for the upper slope.

As for the lower slope, Fig. 11b indicates that FEWS-landslide method with QPF input gives FS $<1$ at $t=25 \mathrm{~h}$, suggesting that landslide is expected to occur at $t=28 \mathrm{~h}$. The 


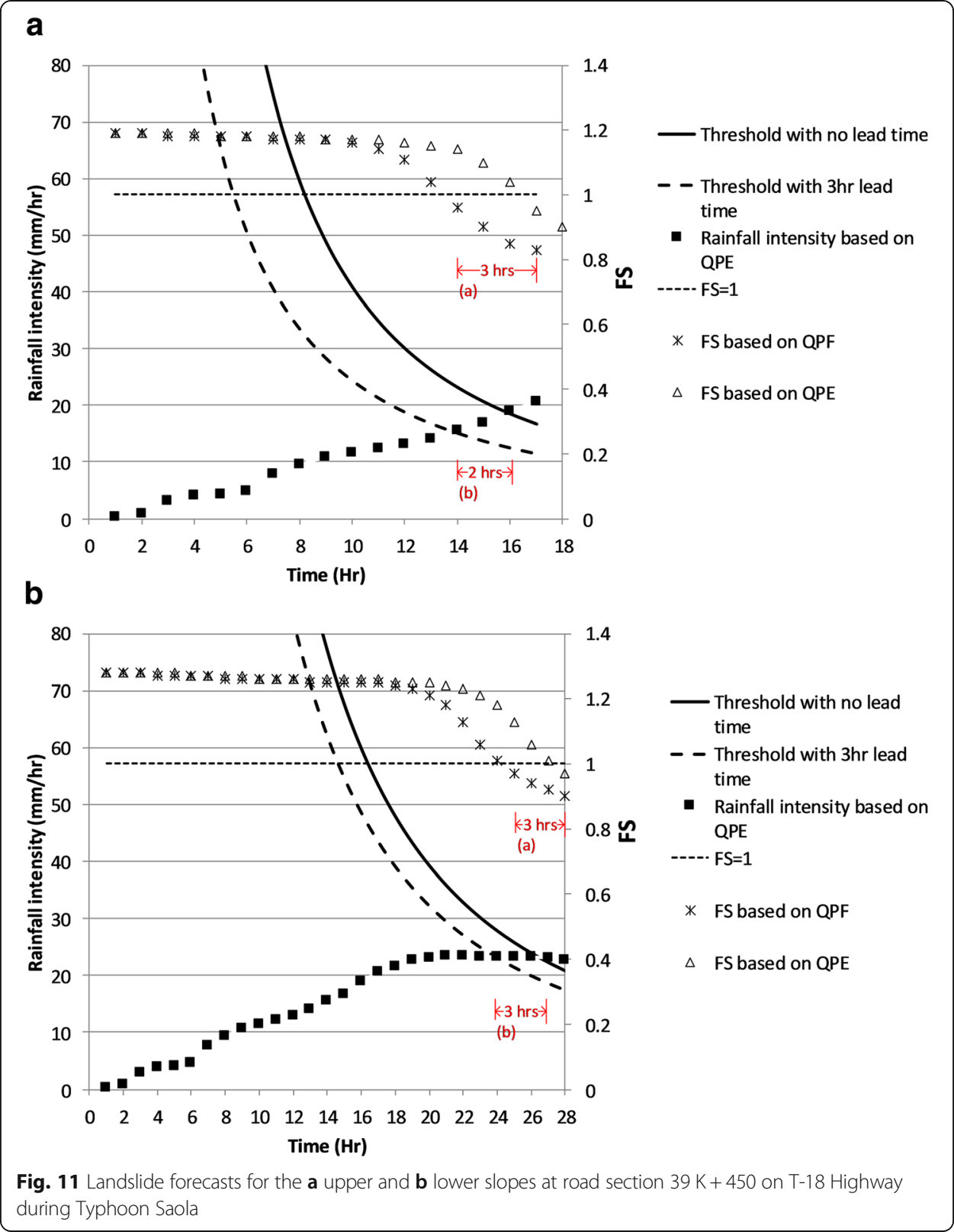

real-time simulation model with nowcast QPE input also indicates that the slope might fail at $\mathrm{t}=28 \mathrm{~h}$. Thus, FEWS-landslide method produces a correct landslide forecast.

On the other hand, Fig. 11b shows that the rainfall threshold-based method suggests that the slope failure might occur $3 \mathrm{~h}$ after $t=24 \mathrm{~h}$. Coincidentally, the trace curve of rainfall intensity intersects 0 -h threshold curve at $t=27 \mathrm{~h}$. This indicates that the rainfall threshold-based method also produced a correct landslide forecast for the lower slope during Typhoon Saola.

Although FEWS-landslide method issues a warning at $\mathrm{t}=25 \mathrm{~h}$ for the lower slope, which is one hour later than the rainfall threshold-based method, however, considering the value of FS at $\mathrm{t}=24 \mathrm{~h}$ is very close to unity, a warning could probably be issued at $\mathrm{t}=24 \mathrm{~h}$ in practice. 


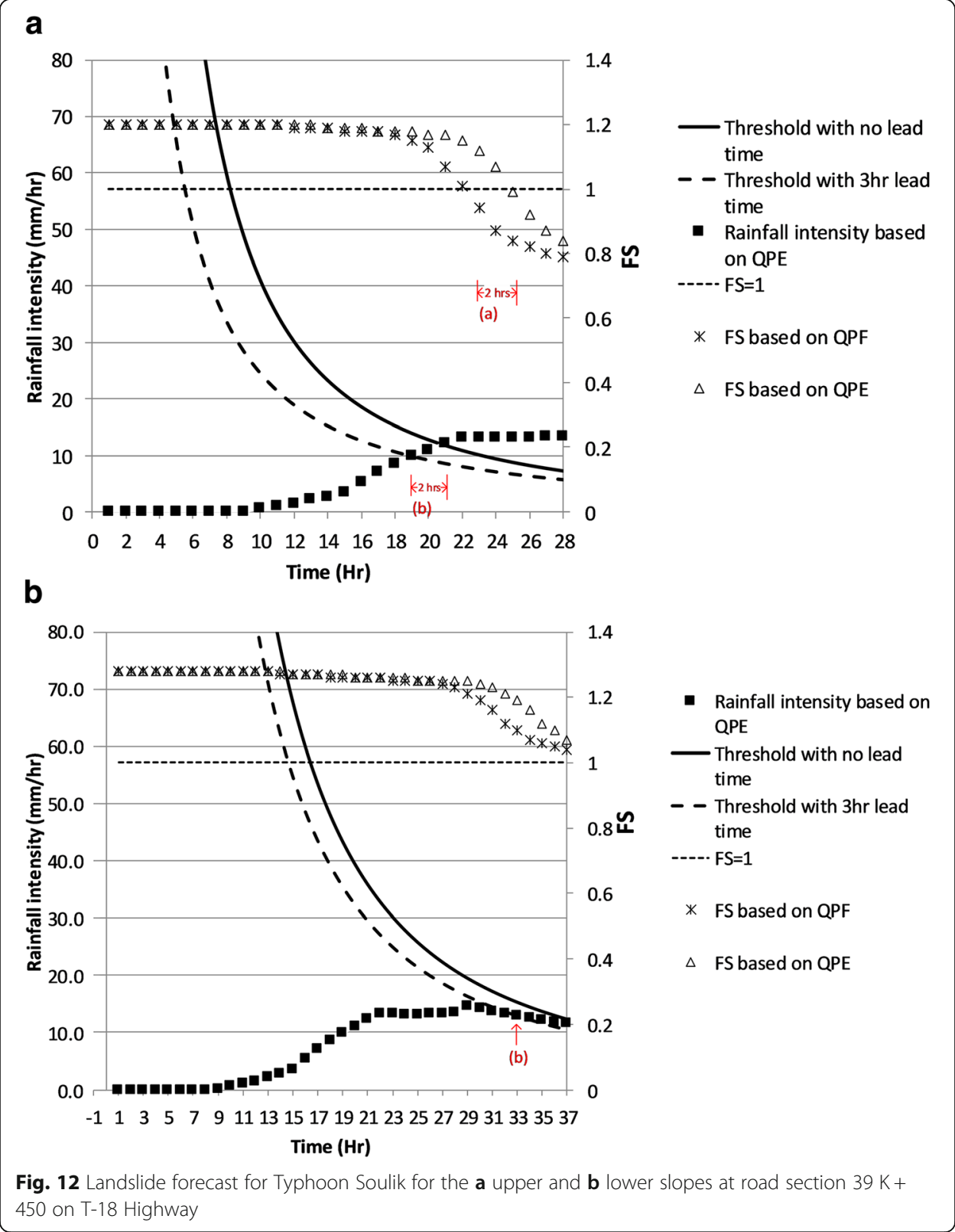

\section{Typhoon Soulik}

Figure 12a shows the time variation of FS in the upper slope by FEWS-landslide method with QPF input during Typhoon Soulik. It shows that the FS value drops below 1.0 at $t=23 \mathrm{~h}$, suggesting that landslide would occur in the upper slope at $t=26 \mathrm{~h}$. The real-time simulation model with the QPE input shows that the landslide occurs at $t=25 \mathrm{~h}$ indicating that the use of QPF might issue a late warning by one hour.

Figure 12a also shows that the rainfall threshold-based method suggests that landslide would occur in the upper slope 3-h after $t=19 \mathrm{~h}$ at which rainfall intensity-duration trace curve intersects with the $t_{l}=3$-h lead-time threshold curve. However, the rainfall intensity trace curve meets the $t_{l}=0$-h threshold curve $2 \mathrm{~h}$ later at $t=21 \mathrm{~h}$. In this case, the rainfall threshold-based method provides warning 1-h later than the anticipated failure time for the upper slope. 
For the lower slope, Fig. 12b reveals that FEWS-landslide method with forecast QPF input yields FS $>1$ throughout the rainfall event, suggesting the landslide would not occur. The real-time simulation model with nowcast QPE input also reveals the same indication about landslide forecast during Soulik event for the lower slope.

Interestingly, Fig. 12b shows that the rainfall threshold-based method suggests that lower slope would fail $3 \mathrm{~h}$ after $t=33 \mathrm{~h}$. However, continuation of rainfall intensity curve would not intersect the $t_{l}=0$-h lead-time threshold curve at $t=36 \mathrm{~h}$, indicating that failure in the lower slope did not occur as anticipated.

\section{Summary and conclusions}

With the aid of a physical-based rainfall-triggered landslide model, this study compared the landslide forecast capability of two methods, namely, rainfall threshold-based method and real-time simulation method. Heavy rainfall during three typhoon events were used to examine landslide early warning performance by the two methods for two slopes at the road section $39 \mathrm{~K}+450$ on Highway T-18 in southern Taiwan. Results of numerical study from the three typhoon events showed that both landslide forecast methods perform satisfactorily with respect to the predicted slope failure times, despite some minor discrepancies. This is expected as any model or method used is subject to a certain level of simplification of reality. Moreover, rainfall nowcast and forecast errors can further contribute to uncertainty in predicting landslide occurrences and slope failure time.

The information provided by the rainfall threshold-based method may be sufficient to facilitate some decision-making with regard to landslide hazard mitigation. Landslide forecast using rainfall threshold curves has the advantage of being simple to implement with real-time rainfall monitoring during a storm event. However, the method possesses some intrisic limitations including: (Baum et al. 2002) site-specific threshold curves have to be derived in advance for each concerned slope individually and the establishment of such curves could be a time-consuming task for large number of slopes; (Cai and Ugai 2004) threshold curves may have to be revised if physical features of the slope change; (Carrara 1988) threshold curves derived from regression analysis using multiple rainfall events are subjected to uncertainty because it is not made for a specific rainfall event; and (Carrara et al. 1992) thresholds provide qualitative information with regard to whether a slope will fail or not, but cannot offer quantitative information with regard to the level of slope safety.

FEWS-landslide method, on the other hand, can offer time-variant forecast of factor of safety of a single or multiple slopes under consideration that can be visualized on screen for assisting decision making. It also possesses some shortcomings including: (Baum et al. 2002) the accuracy of the method in calculating FS is largely affected by the accuracy of model parameters and rainfall inputs from forecasts; and (Cai and Ugai 2004) on-site real-time monitoring facilities are essential for satisfactory forecast of FS which could be too financially expensive for widespread deployment.

Numerical applications of the two landslide forecast methods utilizing physical-based rain-triggered shallow landslide model, along with nowcast and forecast rainfalls during three typhoon rainstorm events, show relative satisfactory and consistent results in predicting slope failure time. From the viewpoint of early warning of landslide, the two 
methods have comparable performance. To choose between the two, one might wish to consider the limitations of the two methods outlined above. Without record on landslide occurrence time for verification, the true accuracy of the two methods at the study site cannot be assessed. However, they can still be regarded as viable tools to facilitate landslide early warning and hazard mitigation provided that the physical-based landslide model is properly calibrated and validated for the concerned sites.

\section{Abbreviations}

Delft-FEWS: Delft - Flood Early Warning System; FS: Factor of safety; QPE: Quantitative precipitation estimation; QPF: Quantitative precipitation forecast; TRIGRS: Transient Rainfall Infiltration and Grid-based Regional Slope-Stability Analysis

\section{Acknowledgements}

The authors would like to acknowledge the support provided by the CECI Engineering Consultants, Inc., Taiwan for providing DEM, geology and borehole data.

Funding

This research was funded by the CECI Engineering Consultants, Inc., Taiwan.

\section{Availability of data and materials}

The datasets generated during the current study are available from the corresponding author on reasonable request.

\section{Authors' contributions}

CCH: providing QPE and QPF data, landslide model and FEWS system integration. CYL: acquisition of data and data collection, slope stability analysis. HYC: interpretation of results, writing of paper. TYK: critical revision and writing of paper. YJC: study conception, works organization. All authors read and approved the final manuscript.

\section{Competing interests}

The authors declare that they have no competing interests.

\section{Publisher's Note}

Springer Nature remains neutral with regard to jurisdictional claims in published maps and institutional affiliations.

\section{Author details}

${ }^{1}$ National Taiwan University, Taipei City, Taiwan. ${ }^{2}$ National Taipei University of Technology, Taipei City, Taiwan.

${ }^{3}$ National Chiao Tung University, Hsinchu City, Taiwan.

Received: 2 July 2018 Accepted: 16 October 2018

Published online: 29 October 2018

\section{References}

Baum RL, Savage WZ, Godt JW (2002). TRIGRS-a Fortran program for transient rainfall infiltration and grid-based regional slope-stability analysis. Open file report 02-424, US Geological Survey, VA

Cai F, Ugai K (2004) Numerical analysis of rainfall effects on slope stability. Int J Geomech 4(2):69-78

Carrara A (1988) Multivariate models for landslide hazard evaluation - a black box approach. Workshop on Natural Disasters in European Mediterranean Countries, Perugia, pp 205-224

Carrara A, Cardinali M, Guzzetti F (1992) Uncertainty in assessing landslide hazard and risk. ITC J 2:172-183

Collins BD, Znidarcic D (2004) Stability analyses of rainfall induced landslides. J Geotech Geoenviron Eng 130(4):362-372

Crosta GB, Frattini P (2003) Distributed modeling of shallow landslides triggered by intense rainfall. Nat Hazards Earth Syst Sci 3:81-93

D'Odorico P, Fagherazzi S, Rigon R (2005) Potential for landsliding: dependence on hyetograph characteristics. J Geophys Res 110:F01007. https://doi.org/10.1029/2004JF000127

Dai FC, Lee CF, Ngai YY (2002) Landslide risk assessment and management: an overview. Eng Geol 64(1):65-87

Ermini L, Catani F, Casagli N (2005) Artificial neural networks applied to landslide susceptibility assessment. Geomorphology 66(1-4):327-343

Frattini P, Crosta GB, Fusi N, Negro PD (2004) Shallow landslides in pyroclastic soil: a distributed modeling approach for hazard assessment. Eng Geol 73:277-295

Fredlund DG, Morgenstern NR, Widger RA (1978) The shear strength of unsaturated soils. Can Geotech J 15:313-321

Gabet EJ, Dunne T (2003) A stochastic sediment supply model for a steep Mediterranean landscape. Water Resour Res 39(9): $1237(1-12)$

ladanza C, Trigila A, Napolitano F (2016) Identification and characterization of rainfall events responsible for triggering of debris flows and shallow landslides. J Hydrol 541:230-245

Iverson RM (2000) Landslide triggering by rain infiltration. Water Resour Res 36:1897-1910

Keim RF, Skaugset AE (2003) Modelling effects of forest canopies on slope stability. Hydrol Process 17:1457-1467

Lan HX, Lee CF, Zhou CH, Martin CD (2005) Dynamic characteristics analysis of shallow landslides in response to rainfall event using GIS. Environ Geol 47:254-267 
Lee S, Choi J (2004) Landslide susceptibility mapping using GIS and the weight-of-evidence model. Int J Geogr Inf Sci 18(8): $789-814$

Petley DN (2008) The global occurrence of fatal landslides in 2007. First World Landslide Forum Satellite Conf, Sendai, p 11 Piciullo L, Calvello M, Cepeda JM (2018) Territorial early warning systems for rainfall-induced landslides. Earth-Sci Rev 179: 228-247

Salciarini D, Tamagnini C (2015) Physical based rainfall thresholds for shallow landslide initiation at regional scales. Eng Geol Soc Territ 2:1041-1044

Schilirò L, Esposito C, Mugnozza GS (2015) Evaluation of shallow landslide triggering scenarios through a physical-based approach: an example of application in the southern Messina area (North-Eastern Sicily, Italy). Nat Hazards Earth Syst Sci 3:2975-3022

Segoni S, Rosi A, Rossi G, Catani F, Casagli N (2014) Analyzing the relationship between rainfalls and landslides to define a mosaic of triggering thresholds for regional-scale warning systems. Nat Hazards Earth Syst Sci 14:2637-2648

Tarantino A, Mongiovi L, Bosco G (2000) An experimental investigation on the isotropic stress variables for unsaturated soils. Géotech 50(3):275-282

Tsai TL (2008) The influence of rainstorm pattern on shallow landslide. Environ Geol 53(7):1563-1570

Tsai TL, Chen HE, Yang JC (2008) Numerical modeling of rainstorm-induced shallow landslides in saturated and unsaturated soils. Environ Geol 55:1269-1277

Tsai TL, Wang JK (2011) Examination of influences of rainfall patterns on shallow landslides due to dissipation of matric suction. Environ Earth Sci 63:65-75

Tsai TL, Yang JC (2006) Modeling of rainfall-triggered shallow landslide. Environ Geol 50:525-534

van Westen CJ, Asch TWJ, Soeters R (2006) Landslide hazard and risk zonation-why is it still so difficult? Bull Eng Geol Environ 65:167-184

Wang WD, Xie CM, Du XG (2009) Landslides susceptibility mapping based on geographical information system, GuiZhou, South-West China. Environ Geol 58(1):33-43

Wu W, Sidle RC (1995) A distributed slope stability model for steep forested basins. Water Resour Res 31:2097-2110

Submit your manuscript to a SpringerOpen ${ }^{\circ}$ journal and benefit from:

- Convenient online submission

- Rigorous peer review

- Open access: articles freely available online

- High visibility within the field

- Retaining the copyright to your article

Submit your next manuscript at $\boldsymbol{\nabla}$ springeropen.com 